UCRL-ID-129078

\title{
Empirical Evaluation of the Radiative Cooling Coefficient for Krypton Gas in the FTU Plasma
}

K. B. Fournier, D. Pacella, B. C. Gregory, M. J. May, G. Mazzitelli, L. Gabellieri, M. Leigheb, M. Finkenthal, D. Stutman, V. Soukanovskii, W. H. Goldstein

November 18, 1997

This is an informal report intended primarily for internal or limited external distribution. The opinions and conclusions stated are those of the author and may or may not be those of the Laboratory.

Work performed under the auspices of the U.S. Department of Energy by the Lawrence Livermore National Laboratory under Contract W-7405-Eng-48. 


\section{DISCLAIMER}

This document was prepared as an account of work sponsored by an agency of the United States Government. Neither the United States Government nor the University of California nor any of their employees, makes any warranty, express or implied, or assumes any legal liability or responsibility for the accuracy, completeness, or usefulness of any information, apparatus, product, or process disclosed, or represents that its use would not infringe privately owned rights. Reference herein to any specific commercial product, process, or service by trade name, trademark, manufacturer, or otherwise, does not necessarily constitute or imply its endorsement, recommendation, or favoring by the United States Government or the University of California. The views and opinions of authors expressed herein do not necessarily state or reflect those of the United States Government or the University of California, and shall not be used for advertising or product endorsement purposes.

This report has been reproduced directly from the best available copy.

Available to DOE and DOE contractors from the Office of Scientific and Technical Information

P.O. Box 62, Oak Ridge, TN 37831

Prices available from (615) 576-8401, FTS 626-8401

Available to the public from the

National Technical Information Service

U.S. Department of Commerce 5285 Port Royal Rd.,

Springfield, VA 22161 


\title{
Empirical Evaluation of the Radiative Cooling Coefficient for Krypton Gas in the FTU Plasma
}

\author{
K. B. Fournier, D. Pacella ${ }^{\mathrm{b}}$, B. C. Gregory, ${ }^{\mathrm{b}, \mathrm{d}}$, M. J. May ${ }^{\mathrm{c}}$, \\ G. Mazzitelli ${ }^{\mathrm{b}}$, L. Gabellieri ${ }^{\mathrm{b}}$, M. Leigheb ${ }^{\mathrm{b}}$, M. Finkenthal ${ }^{\mathrm{c}}$, \\ D. Stutman ${ }^{\mathrm{c}}$, V. Soukanovskii ${ }^{\mathrm{c}}$ and W. H. Goldstein ${ }^{\mathrm{a}}$
}

a Lawrence Livermore National Laboratory, Livermore, California, 94551, USA

b Frascati Tokamak Upgrade, Associazione EURATOM-ENEA sulla Fusione, Centro Ricerche Frascati

c The Johns Hopkins University, Baltimore, MD, 21218, USA

d On leave from INRS and CCFM, Varennes, Canada

\section{ABSTRACT}

For future fusion reactors, a careful balance must be achieved between the cooling of the outer plasma via impurity radiation and the deleterious effects of inevitable core penetration by impurity ions. We have injected krypton gas into the Frascati Tokamak Upgrade (FTU) plasma. The measured visible bremsstrahlung and bolometric signals from krypton have been inverted and the resulting radial impurity density profile and power loss profile for krypton gas are extracted. Using the measured electron density and temperature profiles, the radiative cooling coefficient for krypton is derived. The level of intrinsic impurities (Mo, Cr, $\mathrm{Mn}$ and $\mathrm{Fe}$ ) in the plasma during the krypton puffing is monitored with a VUV SPRED spectrometer. Models for krypton emissivity from the literature are compared to our measured results. 


\section{The Experiment}

The Frascati Tokamak Upgrade (FTU) is a high magnetic field, high electron density tokamak (Fig. 1). The major radius of the torus, $R$, is $0.93 \mathrm{~m}$ and the minor radius, $a$, is $0.3 \mathrm{~m}$. Two krypton $(\mathrm{Kr}, \mathrm{Z}=36)$ injections were made in June of 1997. For those shots (13050 and 13060 ) the plasma current, $I_{p}$ was $500 \mathrm{kA}$, the toroidal field, $B_{T}$ was $5.2 \mathrm{~T}$ and the average electron density of the plasma was low for the FTU parameter space, $\left\langle n_{e}\right\rangle=5 \times 10^{19} \mathrm{~m}^{-3}$.

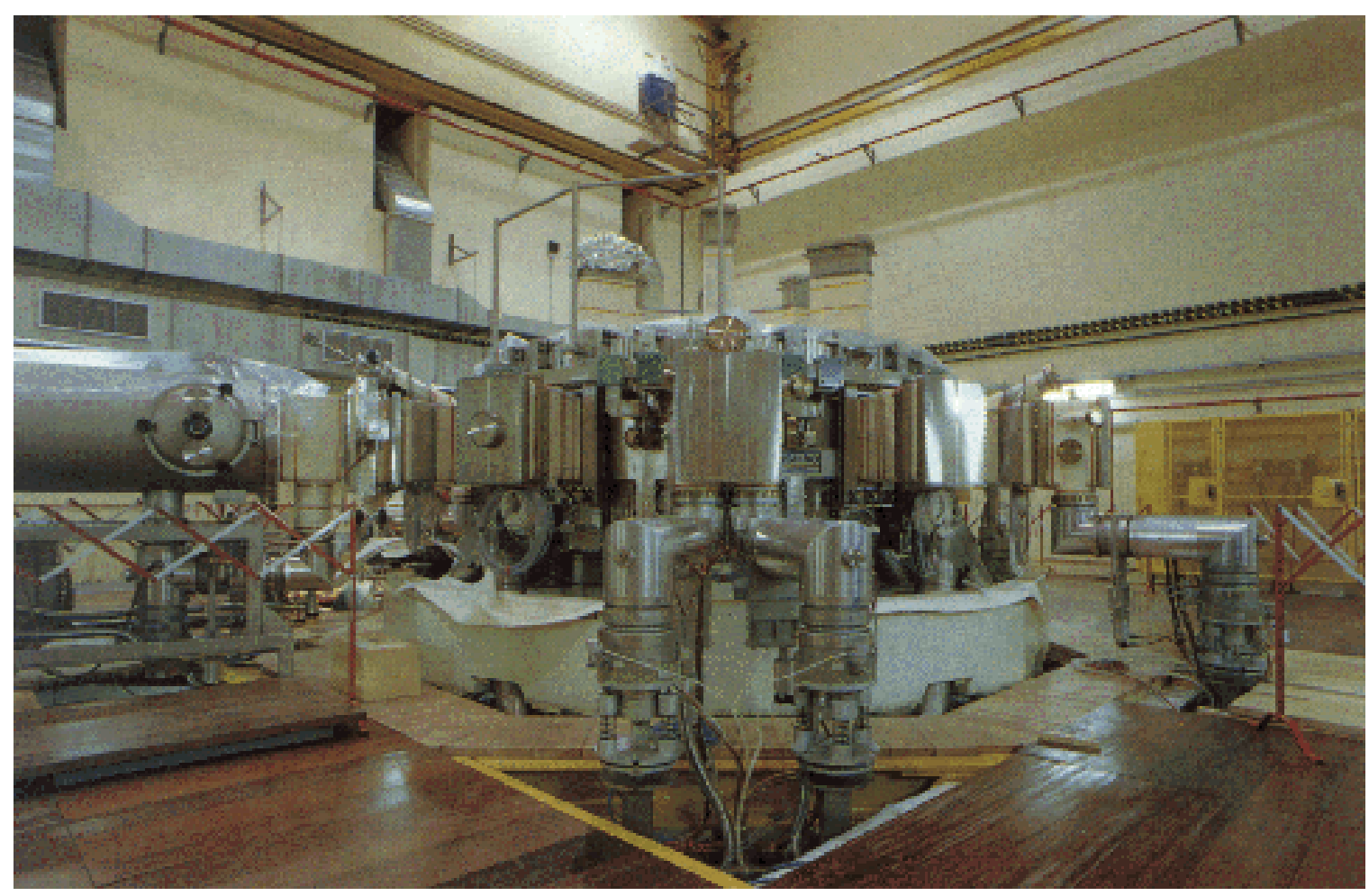

Fig. 1 The Frascati Tokamak Upgrade (FTU).

FTU characteristics

\begin{tabular}{cc}
\hline$R^{\text {maj }}$ & $0.93 \mathrm{~m}$ \\
$a$ & $0.3 \mathrm{~m}$ \\
$B_{T}(\max )$ & $8 \mathrm{~T}$ \\
$I_{P}(\max )$ & $1.6 \mathrm{MA}$ \\
$<n_{e}>$ & 0.3 to $3 \times 10^{20} \mathrm{~m}^{-3}$ \\
$T_{e}$ & 0.7 to $8 \mathrm{keV}$ \\
ECRH & $400 \mathrm{kWatts}$ \\
LH & $1 \mathrm{MWatt}$ \\
\hline
\end{tabular}


Large volumes of $\mathrm{Kr}$ were introduced to the plasma for both shots. The result was that more than $230 \mathrm{msec}$ after the injection, the plasma disrupted. Figure 2 shows the time history of soft $\mathrm{x}-\mathrm{ray}$ emission from the core of the FTU plasma during shot 13060. The $\mathrm{Kr}$ was injected at $\mathrm{t}=0.80$ seconds and the plasma disrupts at $\mathrm{t}=1.03$ seconds.

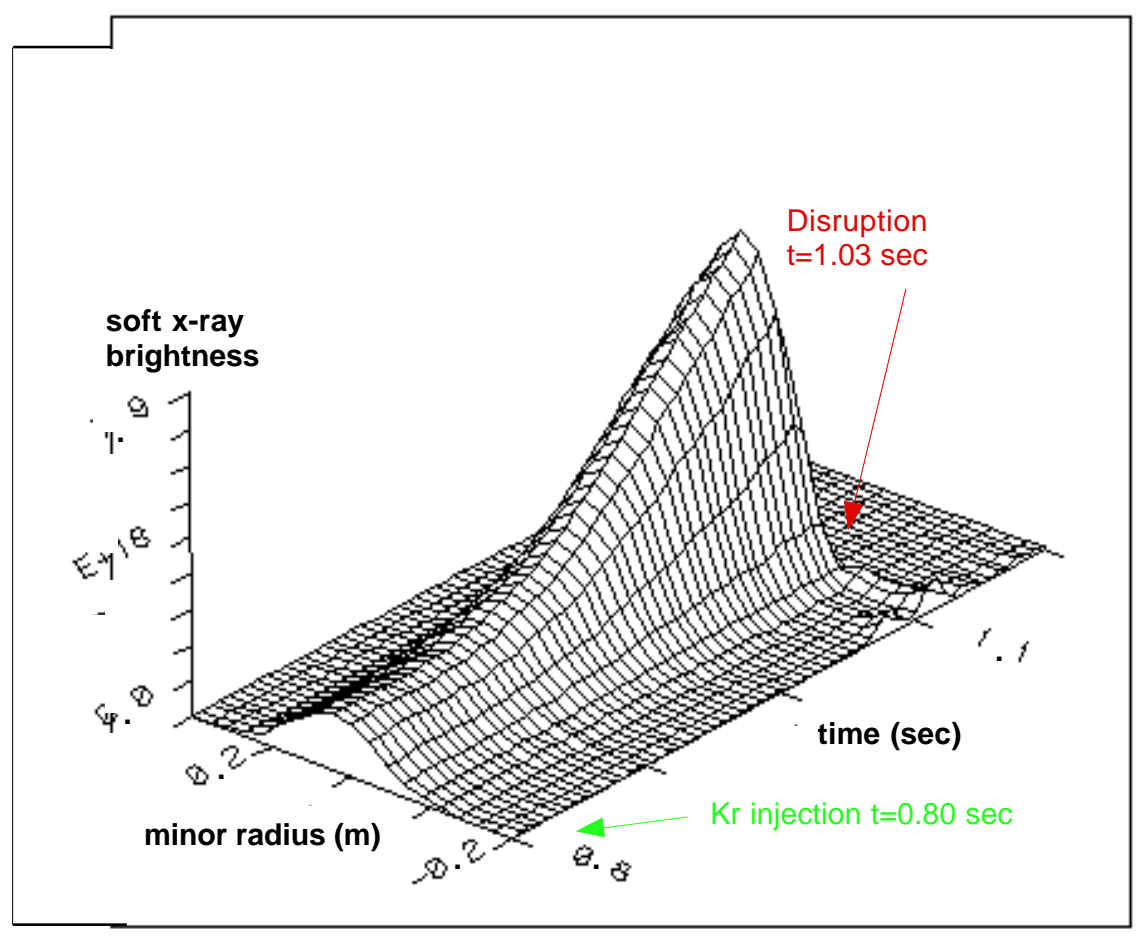

Fig. 2 Temporal and spatial profiles of the soft $x$-ray emission in the FTU plasma (shot 13060). The $\mathrm{Kr}$ was injected at $\mathrm{t}=0.80$ seconds.

The time chosen for the analysis in the present work was $t=1.0$ seconds. The $\mathrm{Kr}$ had been in the plasma $200 \mathrm{msec}$, and the disruption was $30 \mathrm{msec}$ away; the diagnostic systems considered in this work have a time resolution on the order of $\cong 1 \mathrm{msec}$. 


\section{The Model}

We have developed a very simple, analytic model which uses the measured power losses from bolometry and visible bremsstrahlung to derive the density profile and radiative loss coefficient for krypton gas in a high temperature, low density plasma. With this result, we can assess the radiative patterns of $\mathrm{Kr}$ and its penetration behaviour in ohmically heated plasmas. With the empirical value for the $\mathrm{Kr}$ radiation coefficient, we can test different theoretical predictions for the efficiency of $\mathrm{Kr}$ as a cooling channel in a hot plasma. We may also be able to say something interesting about the transport of a high-recycling impurity in a tokamak plasma.

The total power radiated from the plasma and the total power lost by free-free transitions (bremsstrahlung) is given by

$$
\begin{gathered}
P^{\text {Rad }}(r)=n_{e} N_{K r} Q_{K r}\left(T_{e}(r)\right)+n_{e} \sum_{i} N_{Z_{i}} Q_{Z_{i}}\left(T_{e}(r)\right) \\
\varepsilon^{\text {Brems }}(r)=n_{e} N_{K r}<Z_{K r}^{2}>f\left(T_{e}(r)\right)+n_{e} \sum_{i} N_{Z_{i}}<Z_{Z_{i}}^{2}>f\left(T_{e}(r)\right)
\end{gathered}
$$

where $Q_{Z}\left(T_{e}\right)$ is the radiative cooling coefficient for impurity species $\mathrm{Z}$, $\langle Z\rangle$ is the average charge on an impurity ion at temperature $T_{e}, f$ is a slowly varying function of temperature and the sums over $i$ run over all other impurities in the plasma ( $\mathrm{Cr}, \mathrm{Mn}, \mathrm{Fe}, \mathrm{Ni}, \mathrm{Mo}$ and oxygen). Note, $n_{e}, N_{K r},\left\langle Z_{K r}^{2}\right\rangle$, etc. are functions of minor radius.

\section{Observations:}

- The temperature in the plasma changes from $1.8 \mathrm{keV}$ before the $\mathrm{Kr}$ injections to $1.5 \mathrm{keV}$ afterwards.

- During this time, the level of intrinsic impurities is monitored with a VUV SPRED spectrometer and found not to change (Fig. $3)$. 
Since the level of intrinsic impurities and the function $f\left(\mathrm{~T}_{\mathrm{e}}\right)$ do not change significantly during the $\mathrm{Kr}$ injections, the signals from $P^{\text {Rad }}$ and $\varepsilon^{\text {Brems }}$ at some time after the injections can be subtracted from the signal at a time before the injection to yield the contribution from $\mathrm{Kr}$ alone

$$
\begin{gathered}
P^{\text {Rad }}(r)=n_{e} N_{K r} Q_{K r}\left(T_{e}(r)\right) \\
\varepsilon^{\text {Brems }}(r)=n_{e} N_{K r}<Z_{K r}^{2}>f\left(T_{e}(r)\right)
\end{gathered}
$$

The experimental values of $P^{\text {Rad }}$ and $\varepsilon^{\text {Brems }}$ are obtained by means of Abel inversion of the signal from a 13 channel bolometer array and a 12 channel visible bremsstrahlung array.

\section{UVs13060_t0.85}

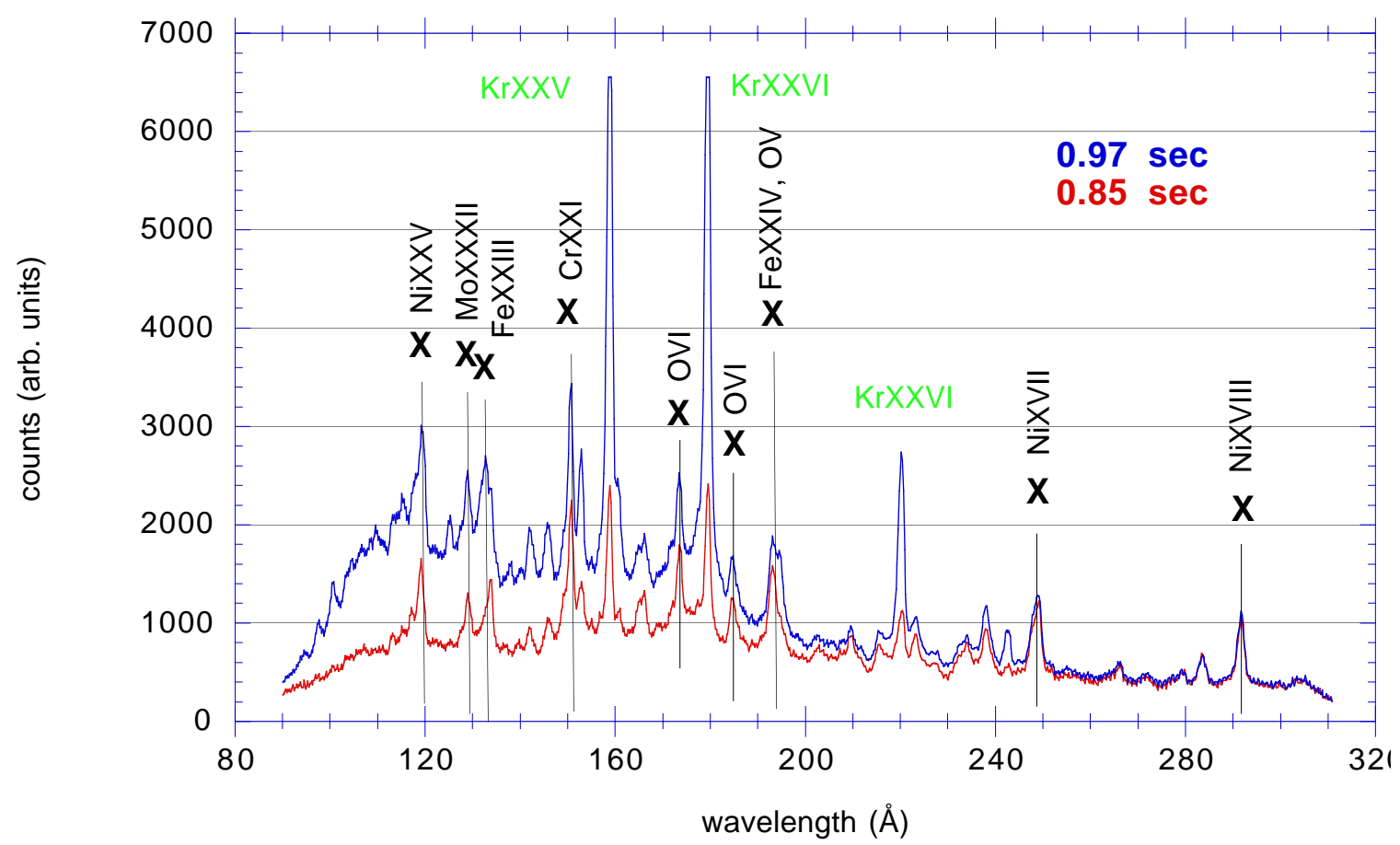

Fig. 3 The SPRED spectrum from shot 13060 at a time before and after the $\mathrm{Kr}$ injection. The lines marked with ' $\mathrm{X}$ ' are from intrinsic impurities and do not change in time. 


\section{Bremsstrahlung Data}

Bremsstrahlung data is from a vertical (12 chord) array. This array looks directly into a port at the bottom of the machine and thus, sees no reflected light. The data from this array at three times during shot 13060 are shown in Fig. 4. The $\mathrm{Kr}$ was injected at 0.8 seconds.

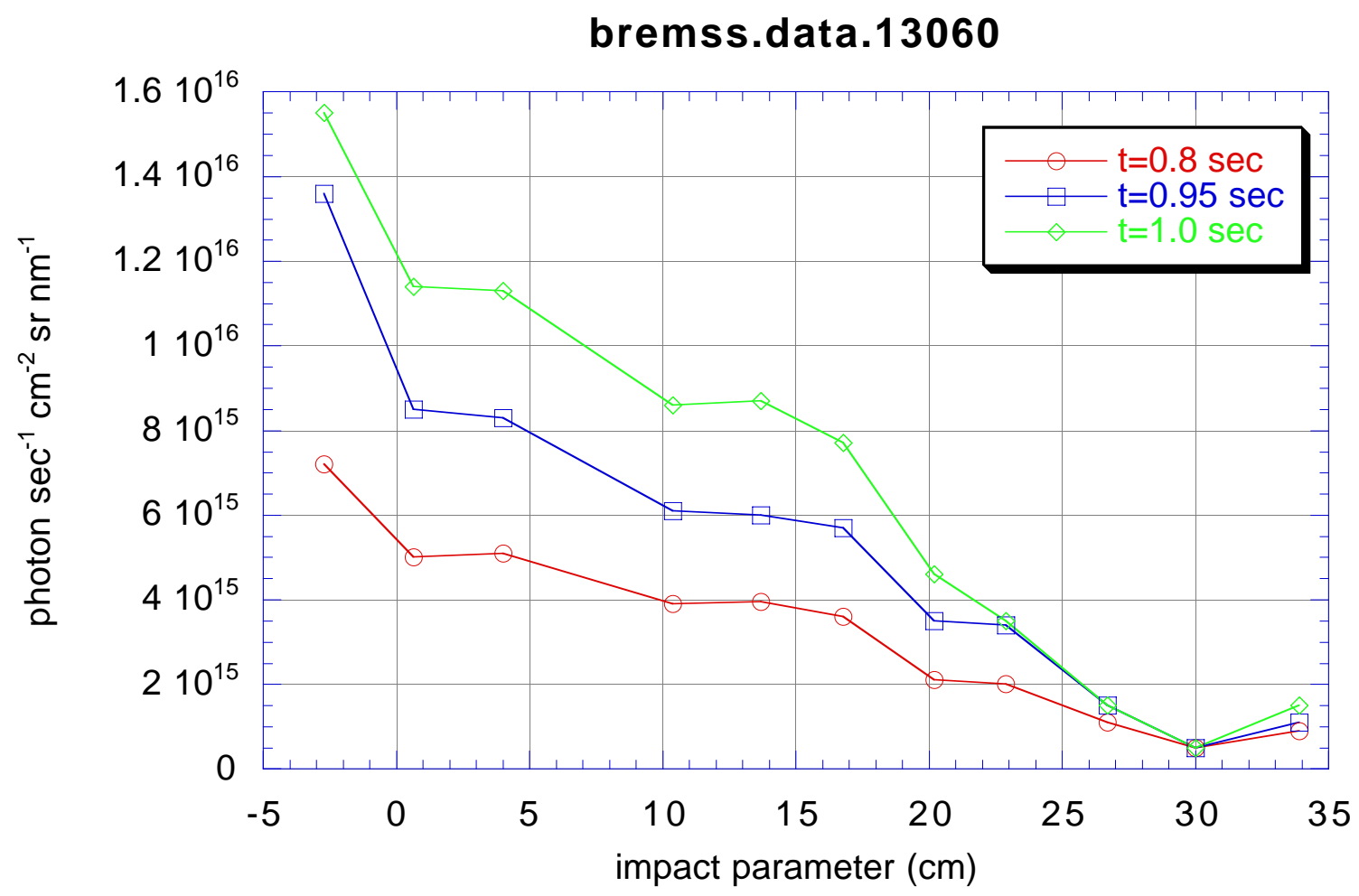

Fig. 4 Brightness seen as a function of viewing chord for the vertical bolometer array. 
We have, according to the definition of $Z_{\text {eff }}$,

$$
n_{e}^{\prime}(r) Z_{e f f}^{\prime}(r)=n_{D}(r)+\sum_{i, j^{\prime}} n_{i, j^{\prime}}(r) Z_{i}^{2}(r)
$$

and with the assumption that the concentration of intrinsic impurities is constant during the time $\mathrm{Kr}$ is in the plasma

$$
n_{e}(r) Z_{e f f}(r)=n_{D}(r)+\sum_{q} N_{q, K r}(r) Z_{q, K r}^{2}(r)+\sum_{i, j^{\prime}} n_{i, j^{\prime}}(r) Z_{i}^{2}(r)
$$

where the primed quantities are for the time before the $\mathrm{Kr}$ injection, the sum over $j$ is over all impurity species other than $\mathrm{Kr}$, the sum over $i$ is over all charge states of each impurity, and the sum over $q$ is over all the ions of $\mathrm{Kr}$.

Thus, taking the difference between the two times,

$$
n_{e}(r) Z_{e f f}(r)-n_{e}^{\prime}(r) Z_{e f f}^{\prime}(r)=N_{K r}(r)\left\langle Z_{K r}^{2}(r)\right\rangle
$$

where the quantity $\left\langle Z^{2}{ }_{K r}\right\rangle$ is the average charge on a $\mathrm{Kr}$ ion at some temperature, $T_{e}$ (see below).

The bremsstrahlung losses from the plasma are given by

$$
\varepsilon_{f f}(r)=\frac{n_{e}^{2}(r) Z_{e f f}(r)}{\kappa} g_{f f} \frac{1}{\lambda^{2} \sqrt{T_{e}(r)}} \exp \left(-\frac{1240}{T_{e}(r) \lambda}\right)
$$

where $T_{e}$ is in $\mathrm{eV}, \lambda=540 \mathrm{~nm}$ and $\kappa$ contains various physical constants. 
By substituting for $Z_{e f f}(\mathrm{r})$ and $Z_{\text {eff }}^{\prime}(\mathrm{r})$ in the equation above, the bremsstrahlung losses from $\mathrm{Kr}$ are given by

$$
\left.\varepsilon_{f f}(t)-\varepsilon_{f f}\left(t^{\prime}\right)=\frac{\overline{n_{e}}}{\kappa \lambda^{2}}\left[\overline{g_{f f}} \frac{1}{\overline{\sqrt{T_{e}(r)}}} \exp \left(-\frac{1240}{T_{e}(r) \lambda}\right)\right] N_{K r}(r) \backslash Z_{K r}^{2}(r)\right\rangle
$$

where $t^{\prime}$ is before the injection, $t$ is after the injection and the quantity in the brackets is the slowly varying function, $f\left(\mathrm{~T}_{\mathrm{e}}\right)$, mentioned above.

\section{Comments:}

- For the electron density, temperature and the Gaunt factor, the quantities with the overbars are found by assuming an average value of the density and temperature for the time before and after the injection.

- The quantity $\varepsilon_{f f}$ is the volumetric power lost due to free-free transitions. The measurements are, of course, line-of-sight integrated and must be inverted. In this case, the difference in the signal at a time before and after the injection is fit to a sum of Zernicke polynomials, and then the inversion is performed.

Data from shot 13060

\begin{tabular}{cccc}
\hline & $\mathrm{t}=0.80 \mathrm{sec}$ & $\mathrm{t}=1.0 \mathrm{sec}$ & \\
$n_{e}(\mathrm{r}=0)$ & $0.9 \times 10^{20} \mathrm{~m}^{-3}$ & $1.3 \times 10^{20} \mathrm{~m}^{-3}$ & $+40 \%$ \\
$T_{e}(\mathrm{r}=0)$ & 1.8 & 1.5 & $-16 \%$ \\
$\mathrm{~g}_{\mathrm{ff}}\left(\mathrm{T}_{\mathrm{e}}\right)$ & 4.12 & 4.02 & $-2 \%$ \\
\hline
\end{tabular}

Thus, using an inversion of the difference in the bremsstrahlung data before and after the $\mathrm{Kr}$ injection, the experimental $T_{e}$ and $n_{e}$ profiles, and the tables of Post et al. (ADNDT, 1977) for $\left\langle Z_{K r}^{2}\right\rangle$ as a function of $T_{e}$, we find the $\mathrm{Kr}$ density profile directly. 
The resulting $\mathrm{Kr}$ density profile is shown in Fig. 5.

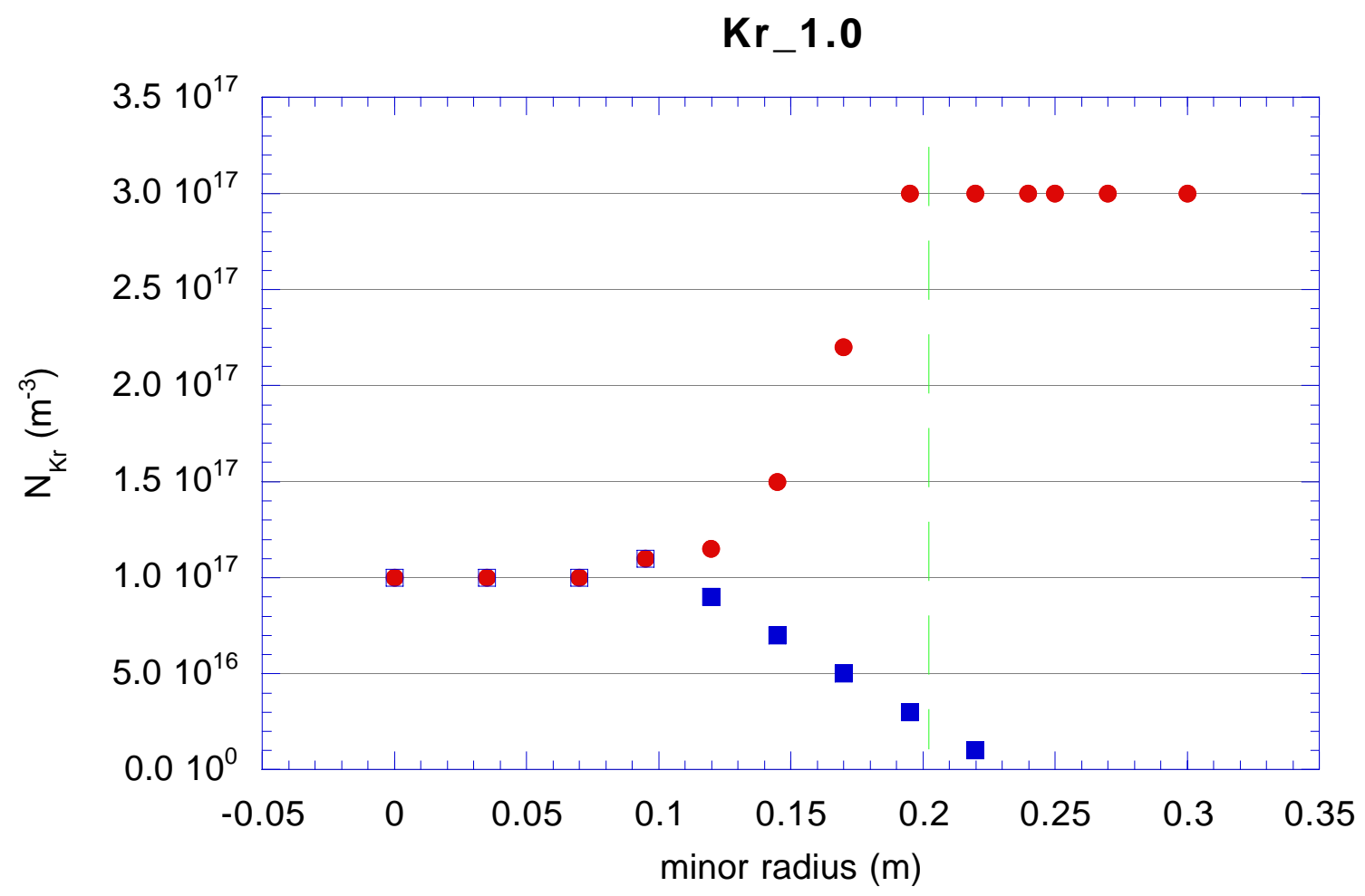

Fig. 5 The radial profile of $\mathrm{Kr}$ at $\mathrm{t}=1.0 \mathrm{sec}$ in shot 13060 (red circles). The blue boxes are an artificial, decreasing profile (discussed below). The green vertical line indicates the limit at which the inverted data are reliable.

Observations:

- The profile indicates that at $\mathrm{t}=1.0 \mathrm{sec}$, the $\mathrm{Kr}$ concentration in the core plasma $(\mathrm{r}<10 \mathrm{~cm})$ is $0.1 \%$ of the central electron density. 
Observations (continued):

- The profile is clearly increasing outwards from the center of the plasma up to the limit of the data. This is consistent with the observations that:

(1) $\mathrm{Kr}$ is a high-recycling impurity. Its source at the plasma's edge does not decay in time, but rather remains quite strong.

(2)It has been observed that there is a transport barrier in the plasma near the half-radius of the FTU (Pacella et al., Plas. Phys. and Controlled Fusion, 1997). This is the position where the large gradient in $\mathrm{N}_{\mathrm{Kr}}$ exists.

A density profile that decreases with radius (consistent with a typical high- $Z$ intrinsic impurity density profile) is indicated by the boxes in Fig. 5. This profile yields results for the Kr radiative cooling coefficient, derived in the section below, which are not consistent with theoretical models (see following section). 


\section{Bolometry Data}

The data from the bolometer array at three times during shot 13060 is shown in Fig. 6.

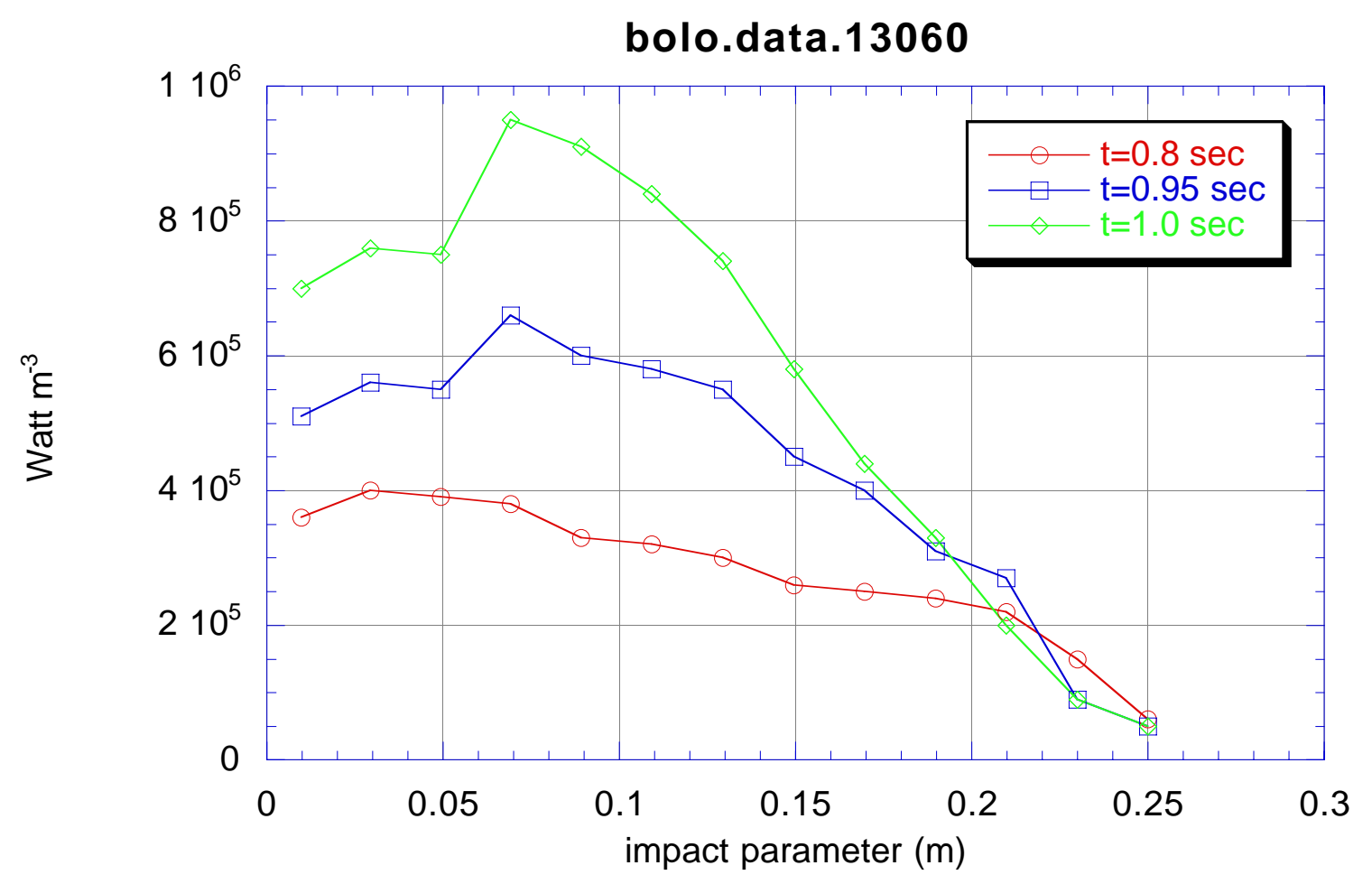

Fig. 6 Brightness seen as a function of viewing chord for the horizontal bolometer array.

\section{Comments:}

- Unlike the bremsstrahlung array, this bolometer array looks horizontally into the plasma and sees the molybdenum tile limiter on the inner wall. (The vertical bolometer array is unavailable for this shot).

- The four chords which have impact parameters from $7 \mathrm{~cm}$ to $13 \mathrm{~cm}$ clearly see an unusual radiation pattern after the $\mathrm{Kr}$ is injected. This radiation is a MARFE.

- The $\mathrm{H}_{\alpha}$ diagnostic array, and a horizontal bremsstrahlung array, which have the same lines of sight as the bolometer array, see the same MARFE. 
Hence, the data for those four chords has been smoothed to $\mathrm{map}$ monotonically from the chord with impact parameter $\rho=15 \mathrm{~cm}$ to the chord with $\rho=5 \mathrm{~cm}$.

- If the data is not smoothed in such a manner, the inversion of the data yields negative volumetric power losses in the core plasma.

- The inversion of the difference between the smoothed data after the $\mathrm{Kr}$ injection and the bolometric data before the $\mathrm{Kr}$ injection yields an excellent fit to the (smoothed) bolometric signal when integrated. Thus, the procedure is selfconsistent.

The inverted data gives us the volumetric radiative loss profile, $P^{R a d}(\mathrm{r})$. With the electron density profile (measured by $\mathrm{DCN}$ ), the electron temperature profile (measured with ECE) and the $\mathrm{Kr}$ density profile derived above, we compute the radiative cooling coefficient for $\mathrm{Kr}$

$$
Q_{K r}\left(T_{e}\right)=\frac{P^{\text {Rad }}(r)}{n_{e}(r) N_{K r}(r)}
$$

The result is shown in Fig. 7. 


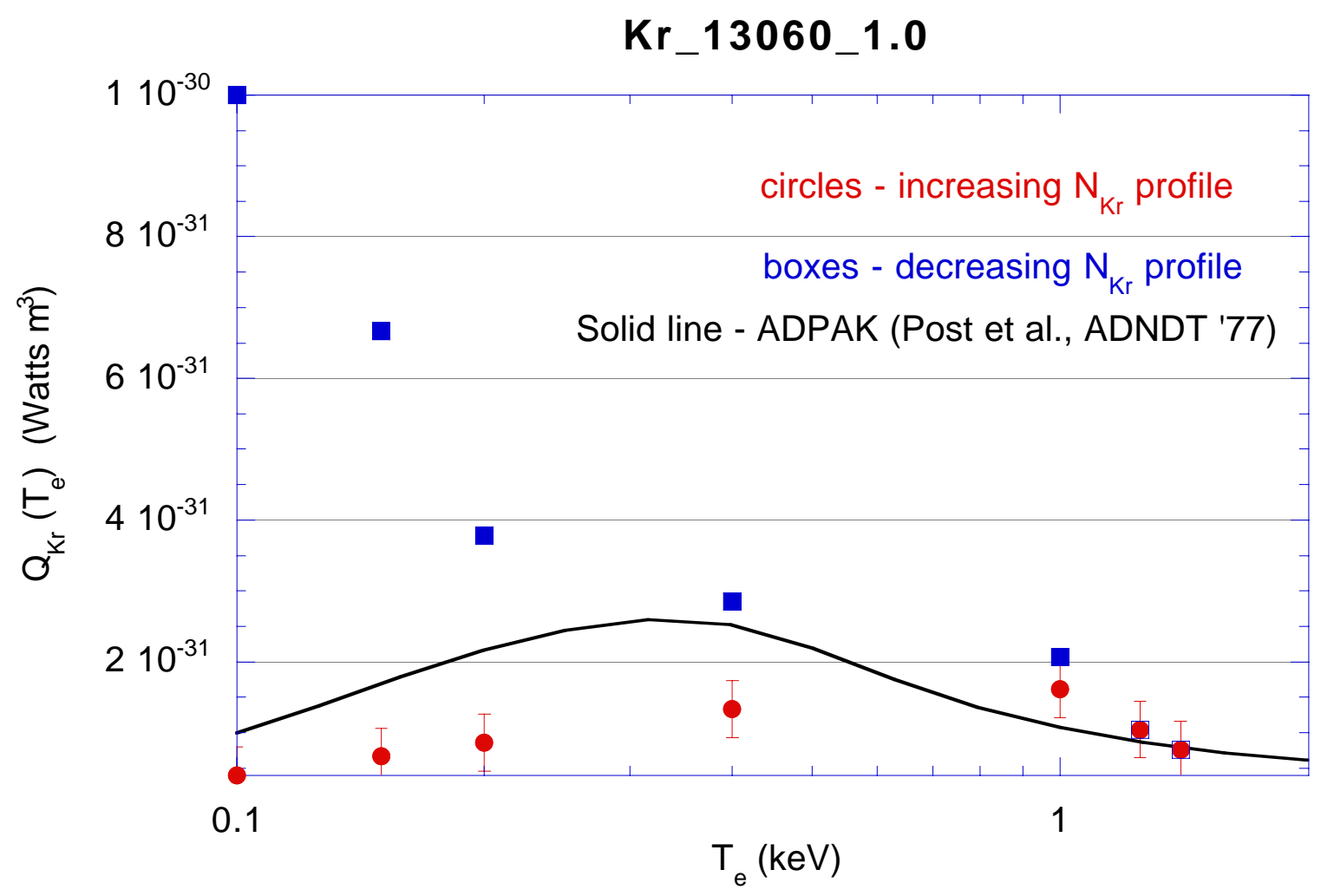

Fig. $7 \mathrm{Kr}$ radiative cooling coefficient for the experimentally derived $\mathrm{Kr}$ profile (red circles), for the artificial, decreasing $\mathrm{Kr}$ profile (red squares) and from the average-ion model of Post et al. (solid line). 


\section{Conclusions}

- We have measured the radiative cooling coefficient of krypton in a tokamak plasma. The amount of $\mathrm{Kr}$ was so large as to cause a disruption of the plasma after $200 \mathrm{msec}$ (Fig. 2); the large amount of $\mathrm{Kr}$ means that the measured bolometric and bremsstrahlung signals are due (almost exclusively) to $\mathrm{Kr}$ (Fig. 3).

- From $300 \mathrm{eV}$ to $1.5 \mathrm{keV}$ good agreement is achieved between our derived cooling coefficient and the theoretical results of Post et al.

- The profile of $\mathrm{Kr}, N_{K r}(\mathrm{r})$, is obtained from the bremsstrahlung data, and is seen to be peaked in the outer part of the plasma. This profile is the only one that yields a cooling coefficient in (qualitative) agreement with the theoretical results of Post et al.

- A transport barrier at the half-radius (where the $T_{e}$ and $n_{e}$ gradients are very large) explains the shape of the profile.

- The same shape of the $\mathrm{Kr}$ profile is seen at times earlier than, and subsequent to, the time we have chosen for analysis.

This work describes a preliminary analysis of two $\mathrm{Kr}$ injections at FTU. Agreement between the results of our model and the theoretical predictions of Post et al. has been achieved within the experimental uncertainties and the approximations used in the analysis. Future experimental work will include further $\mathrm{Kr}$ injections with a smaller volume of gas as well as spectroscopic diagnostics of line transitions in individual ions. Future developments in the analysis will incorporate the measured time variation in the electron temperature and density profiles and an inversion of the bolometric and bremsstrahlung signals at times before and after injection, separately. 


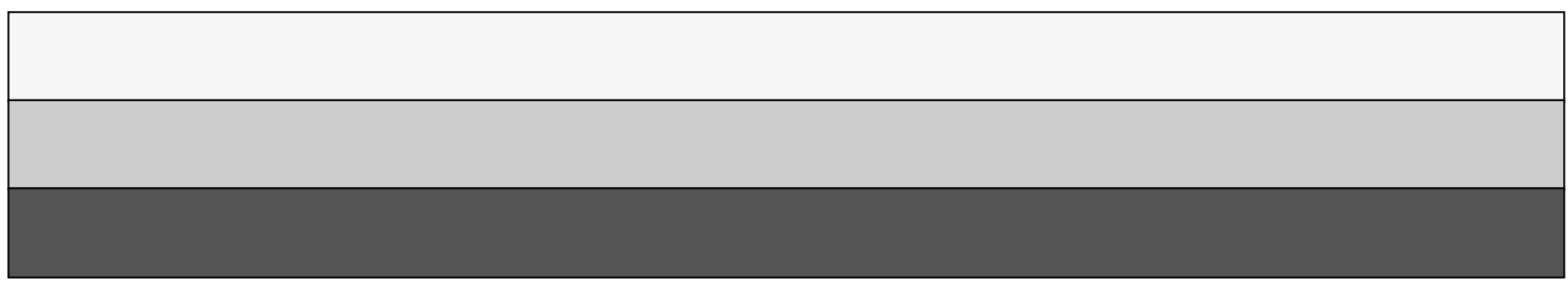

